\title{
Microbiological and environmental factors survey in two laboratory animal facilities from Western Romania
}

\author{
Adina Baias and Romeo T. Cristina* \\ Pharmacology Department, Faculty of Veterinary Medicine, 300645, No. 119, Calea Aradului, Timisoara, Romania.
}

Accepted 19 March, 2013

\begin{abstract}
In Romania, experimentation on laboratory animals is hampered by major deficiencies regarding breeding systems, marketing and use of animals for scientific purposes, the provisions of The European Convention for the Protection of Vertebrate Animals Used for Experimental and Other Scientific Purposes and Directive 63/2010/EEC are not yet respected fully. The aim of this study was to evaluate the microbiology and environment of the housing conditions for animals used for scientific purposes. The survey was accomplished for a period of four months in two laboratory animal facilities located in West of Romania, by measuring the microenvironment physical, chemical and microbiological factors. The registered values of physical and chemical factors in the visited facilities were similar (average temperature $21^{\circ} \mathrm{C}$, relative humidity $55 \%$, objective brightness $118 \mathrm{Ix}$ ), but for recorded microbiological factors values showed great differences: in the A facility, the mean value for total number of mesophilic bacteria was 3,507 C.F.U. $/ \mathrm{m}^{3}$ air, while in the $B$ facility, airborne microorganisms had much greater values: 286,327 C.F.U. $/ \mathrm{m}^{3}$ air. Predominant bacterial species identified were staphylococci.
\end{abstract}

Key words: Laboratory animals, microenvironment factors, survey.

\section{INTRODUCTION}

Adequate housing of animals used in scientific research is an essential condition in order to ensure animal welfare, quality of data obtained from research that includes animals as well as health, and safety of animals used. The environment in which animals are housed is very important for the health of laboratory animals. The American Guide for the Care and Use of Laboratory Animals makes a clear delimitation between the laboratory animal facility environment and the cage in which animals are housed ILAR, 1996). Thus, the microenvironment is described to be the closest space for the animal (usually, the cage), with its own temperature, humidity and a specific composition of gases and airborne microorganisms, while the macroenvironment is represented by the room were the cages are housed or an exterior, outdoor habitat (Kowalski et al., 2002). The microclimate of laboratory animal facilities could be defined as the total physical factors (temperature, humidity, air velocity, lighting, air ionization and noise), chemical factors (oxygen concentration, carbon dioxide, ammonia, sulfide hydrogen and other gases) and biological factors (microorganisms and particles) from the inside of the facility, factors that are interrelated and influence the production and animal health, in a favorable or unfavorable manner, dependent on physiological requirements (Gordon et al., 2001; Brielmeier et al., 2006). A great number of laboratory animal facilities existing in Romania simple cages are used, without a controlled air evacuation system; some species (for example, guinea pig) are housed on permanent bedding where air ventilation system is poor, causing air pollutant loading, etc., so experimentation on laboratory animals in Romania is hampered yet by major deficiencies regarding breeding systems, marketing and use of animals for scientific purposes. As a consequence, the provisions of The European Convention for the Protection of Vertebrate Animals Used for Experimental and Other Scientific Purposes and Directive 63/2010/EEC are not entirely respected. In order to align with the requirements of the International 
Convention and respect the principles agreed in the European Union, researches should characterize the status quo of laboratory animal facilities and how animals are used in experiments, as a prerequisite for developing legislative and administrative measures, and to determine steps to be taken in the near future is needed. The aim of this study was to evaluate the main parameters of microenvironment for animals used for scientific purposes in two laboratory animal facilities from Romania.

\section{MATERIALS AND METHODS}

\section{Micro environmental factors measurements}

Micro environmental factors were measured during a four months period (February to May, 2010), in two laboratory animal facilities, labeled $\mathrm{A}$ and $\mathrm{B}$. For the physical factors (temperature and humidity) a TESTO 435-2 multifunctional device (TESTO, Germany) was used. These parameters were separately determined in each room where mice and rats were housed. Illumination level was determined using a DT 88204 in 1 Multi-function Environment - Meter device (Nanjing T-Bota Scietech Instruments, China). Based on measurements made in several parts of the room, the objective brightness $(\mathrm{OB})$ and a uniformity factor were calculated. Among chemical factors of microclimate, carbon dioxide was determined, using the multifunctional TESTO 435-2 device (TESTO, Germany).

The animals were under a circadian rhythm of $12: 12$, the lights were on at 07:00 h. Their diet was a normal diet for mice and rats. The bedding used was aspen chips.

\section{Particles and airborne microorganisms}

Among biological factors of microenvironment, particles and airborne microorganisms were measured. Dust particles were determined with Met One Model 2408 Laser Particle Counter device (Met One, USA). Measures were made in front of cages. $30 \mathrm{~L}$ of air were aspirated in $10 \mathrm{~min}$.

\section{Air contamination level with bacteria and fungi}

Suction method of a known air volume and impact on culture media was used to retain germs, with a SAS SUPER 100 Microbial Air Sample device (International pbi S.p.A, Italia). The aspirated air volume was $50 \mathrm{~L}$. We used correction tables and calculation formula, provided by SAS SUPER 100 device, to determine the number of bacteria in a cubic meter of air. The calculation formula was:

$\mathrm{X}=\operatorname{Pr} \times 1000 / \mathrm{V}$

Where: $\mathrm{V}=$ volume of sampled air $=50 \mathrm{I}$ of air; $\operatorname{Pr}=$ probable count obtained by positive hole correction; $\mathrm{x}=$ colony forming units per $1000 \mathrm{~L}$ (= 1 cubic metre) of air.

\section{Microbiological indicators}

Total mesophilic aerobic bacteria (TMB), staphylococci, coli forms and fungi were assessed USING common methods used in veterinary hygiene. The used culture media were nutritive agar for TMB, Chapman agar for staphylococci, Levine agar for coli forms and Sabouraud whit antibiotics agar for fungi (Decun et al., 2005).

\section{RESULTS}

\section{Micro environmental factors}

In facility $A$, were housed 80 mice and 230 rats in different rooms. Each conventional animal room had size of $2.50 \times 2.00 \mathrm{~m}$ and height of $3.00 \mathrm{~m}$. In facility $\mathrm{B}$, same room, was housed 20 mice and 44 rats. Measurement places were identical for each facility: at one meter height from the floor surface for temperature and humidity, and at first, last and third level of the racks for animals, for lighting. In the first laboratory animal facility $(A)$, both in mice and rats rooms, the mean temperature was $21^{\circ} \mathrm{C}$, with low variations $\left( \pm 0.3^{\circ} \mathrm{C}\right)$. Also, in the second facility (B), the mean temperature was $21^{\circ} \mathrm{C}$. During cold seasons, with the help of electrical heating systems, air temperature was maintained at the recommended value by the European legislation. Analyzing temperature mean values recorded on daily charts from facilities $A$ and $B$, was found to be around the same average value recorded during the measurements.

In both facilities, relative humidity was $55 \pm 5 \%$. In facility $A$, relative humidity was maintained within acceptable limits, due to artificial ventilation system that eliminates the excess water vapor from the rooms were animals are maintained. In facility $B$, the exhaust ventilation system is represented by a centrally situated fan. In facility $B$, determinations measurements were made during spring season, but in the cold ones, the ventilation system may not be sufficient, thus the air relative humidity could increase. In facility $A$, there is an artificial lighting, provided by two fluorescent lamps of 135 lux (Ix) each. Light period is 12 $\mathrm{h}$ with alternating $12 \mathrm{~h}$ of darkness. In facility $\mathrm{B}$, there are three windows, which provide natural light, and also a central situated fluorescent lamp. In facility A, the objecttive luminosity in mice room was about $118 \mathrm{~lx}$, with the highest value ( $325 \mathrm{Ix}$ ) for the cages situated on the superior levels of racks and the lowest value $(18 \mathrm{~lx})$ for those situated on the lowest level of racks. In facility $B$, due to the natural light, objective luminosity was $420 \mathrm{~lx}$, during daytime. The artificial light source (the fluorescent lamp) was utilized when the natural light is insufficient. The uniformity factor was about $1 / 2.6$ in both facilities. In Table 1 is presented the average values for physic and chemical factors of environment measured in the two surveyed facilities.

In facility $A$, in the mice room, the average value for carbon dioxide concentration was of $620 \mathrm{ppm}$ while in the rat's room, the average value was of $580 \mathrm{ppm}$. In facility B, the carbon dioxide concentration mean value was $552 \mathrm{ppm}$.

In rats room in facility $A$, the mean value of particles with a diameter between 10 and $20 \mu \mathrm{m}$ was 232 particles/air cubic meter, before bedding change, this number rose to a mean value of 587 particle/cubic meter, and, after bedding change, the average value was about 75 particles/cubic meter. For particles with a diameter between 1 and $5 \mu \mathrm{m}$, the mean value was of 9,730 before bedding change, 
Table 1. Average values for physical and chemical factors measured in the two laboratory animals' facilities.

\begin{tabular}{ccccc}
\hline Facility & Temperature $\left({ }^{\circ} \mathbf{C}\right)$ & Relative humidity $(\%)$ & Ojective brightness (Ix) & Carbon dioxide (ppm) \\
\hline A & $21 \pm 0.3$ & $50 \pm 5$ & 118 & 600 \\
B & $21 \pm 0.1$ & $50 \pm 5$ & 420 & 552 \\
\hline
\end{tabular}

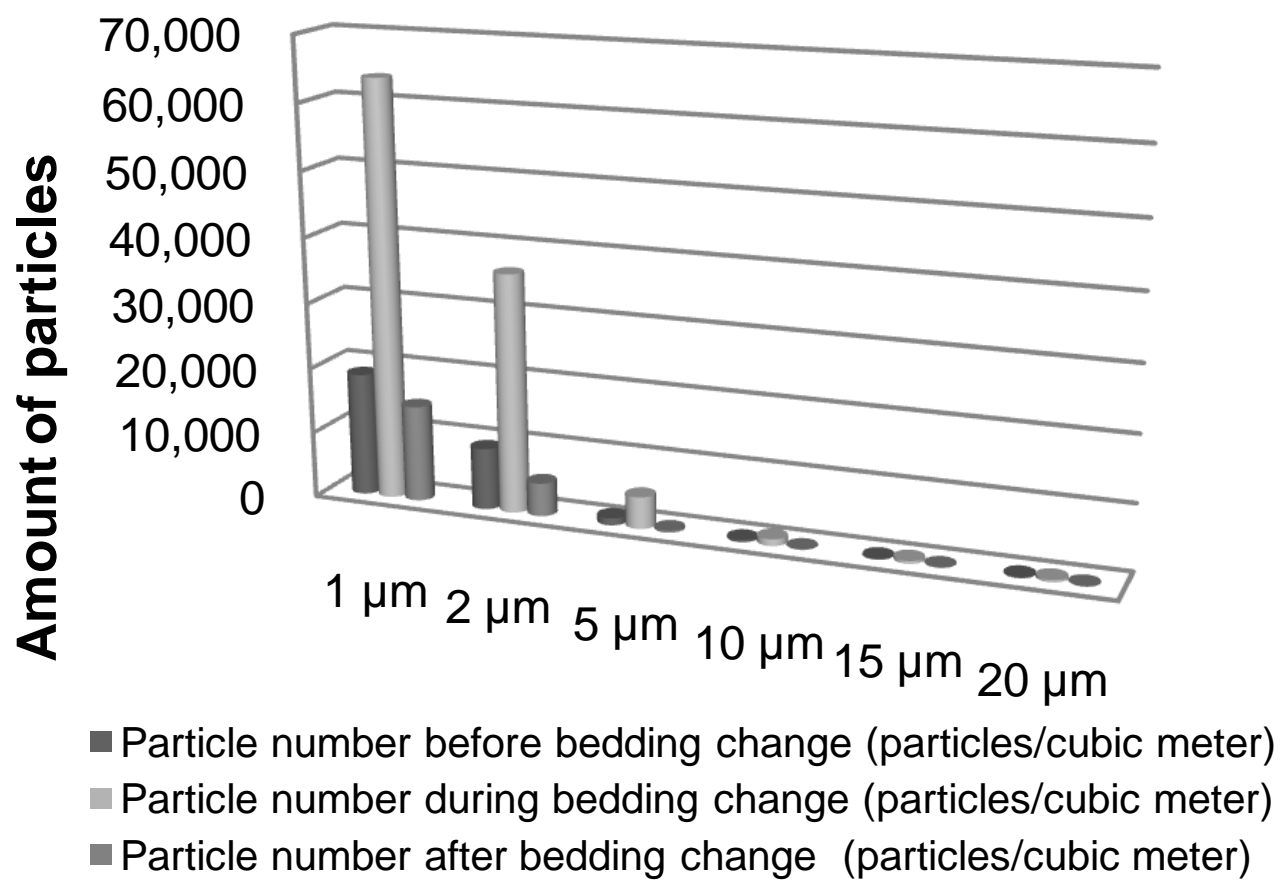

Figure 1. Dynamic of airborne particles in rats in A facility.

during bedding change, this value rose to 35,000 , and, few hours later, this number decrease to 6,670 (Figure 1).

In mice room in facility $A$, the means number of particles with a diameter between 10 and $20 \mu \mathrm{m}$ was 82 particles/air cubic meter, before bedding change, this number rose to a mean value of 257 particle/cubic meter, and, after bedding change, the average value was about 64 particles/cubic meter. For particles with a diameter between 1 and $5 \mu \mathrm{m}$, the mean value was of 8,616 before bedding change, during bedding change, this value raised to 44,628 and, few hours later, this number decrease to 3,287 (Figure 2).

In facility $A$, the bedding change activities led to an increase of dust particles more than three times, but, after changing, the airborne particles number reduced considerably.

In facility $\mathrm{B}$, a higher number of particles/air cubic meter was recorded. For particles with a diameter between 1 and5 $\mu \mathrm{m}$, the particle number recorded before bedding change was 10,504 , during bedding change, it rose to 53,303 and, after few hours, it reduced to 8,808 particles /air cubic meter. For bigger particles, with a diameter between 10 and $20 \mu \mathrm{m}$, the mean value was 637 particles before bedding change, 2,140 during bedding change, and, after a while, the average value decreased to 421 particles/air cubic meter (Figure 3).

In facility A, before bedding change, TMB was 3,507 C.F.U $/ \mathrm{m}^{3}$ air (Table 2), from which staphylococci represented $51 \%$, coli forms represented 3.0 to $6.7 \%$ and fungi about $2.5 \%$.

In facility B, TMB was $286,327 \mathrm{CFU} / \mathrm{m}^{3}$ air, with 20 to $25 \%$ staphylococci, $10 \%$ coli forms and $1 \%$ fungi.

\section{DISCUSSION}

Synergistic relationship between environmental air temperature and relative humidity is important for growth and care of laboratory animals. Animal homeostasis is directly influenced by environmental air temperature. Increases or decreases of environmental temperature are stressors for animals, because it requires additional efforts to maintain homeostasis. Temperatures from both facilities fall within the limits proposed by Directive 86/609/EEC Annex II and the Directive 63/2010/EU of the European Parliament and the Council on protection of animals used for scientific purposes. European legislation stipulates air temperature between 20 and $25^{\circ} \mathrm{C}$ for laboratory animals 


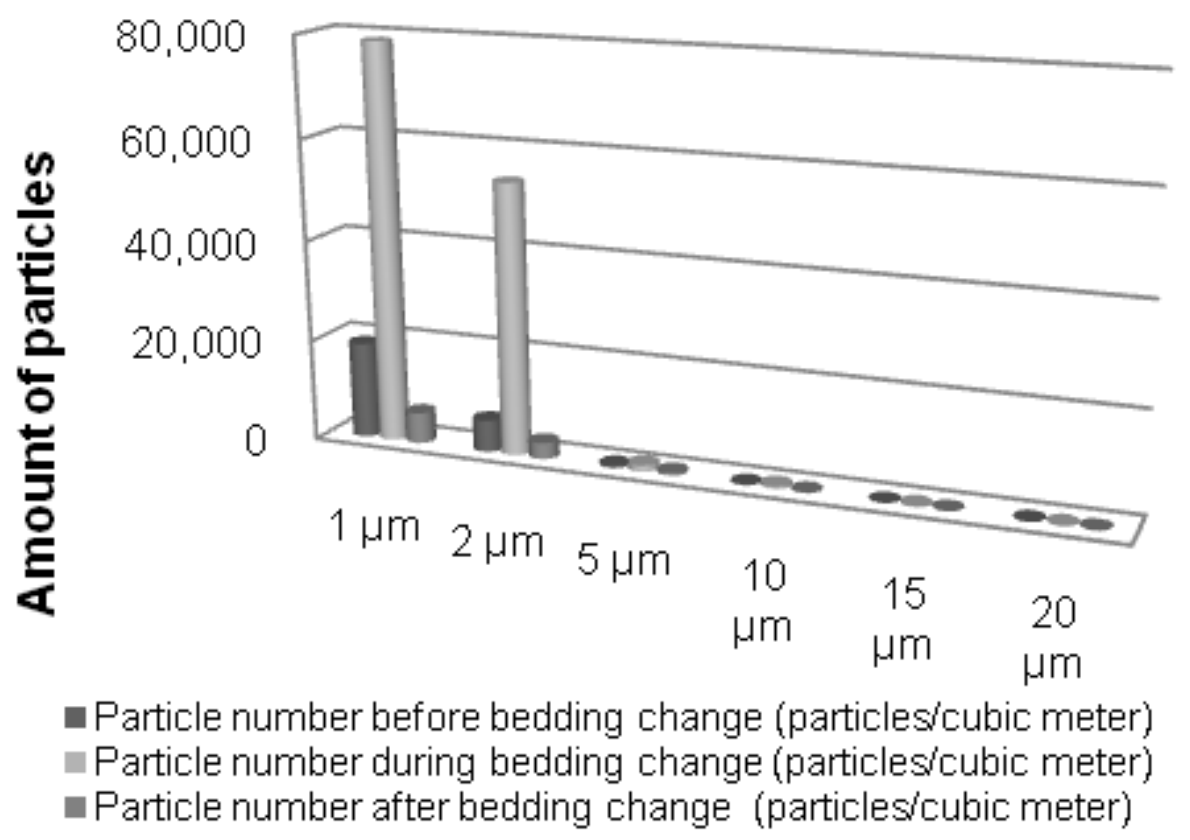

Figure 2. Dynamic of airborne particles in mice in facility $A$.

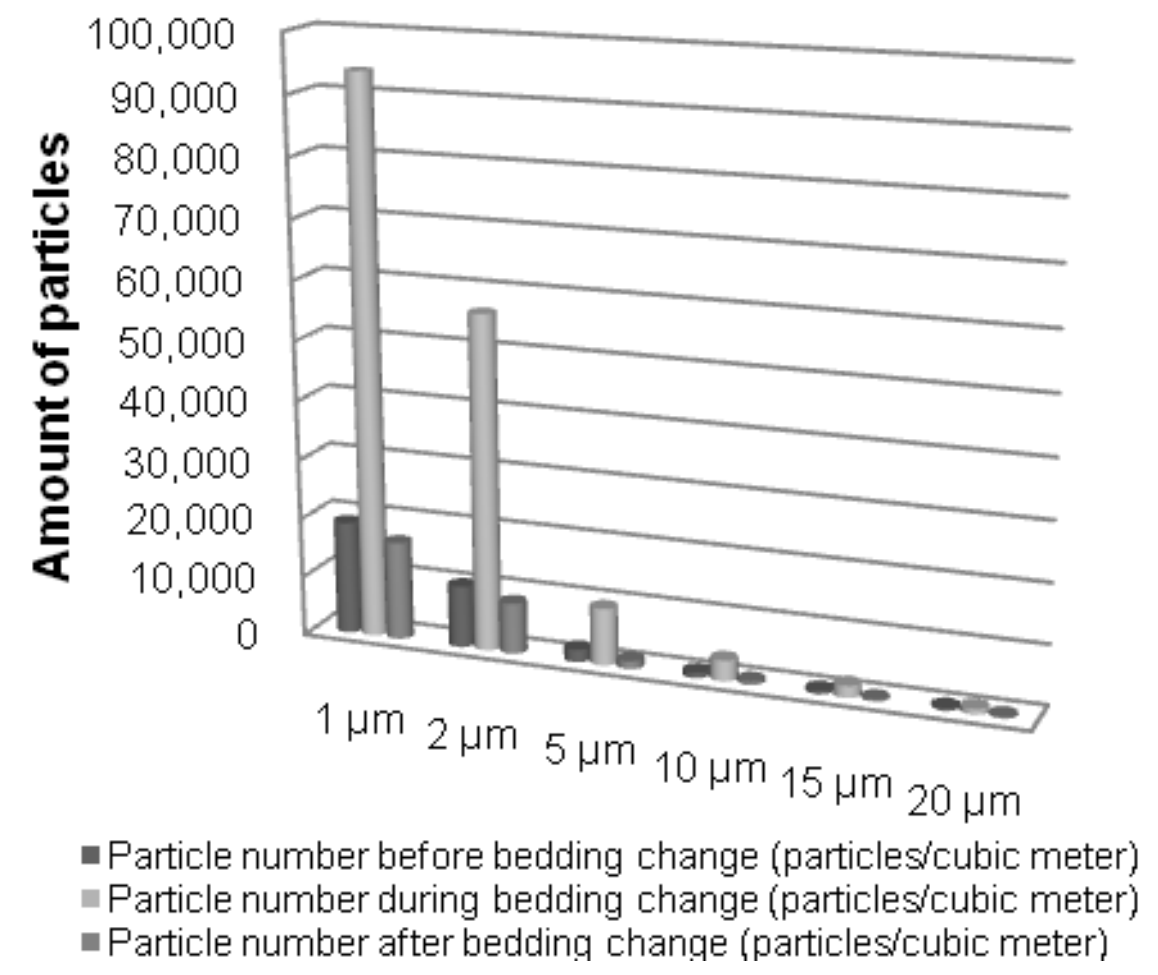

Figure 3. Dynamic of airborne particles in B facility

(mice, rats, rabbits and guinea pigs). Also, air humidity is $50 \pm 10 \%$.

Hydrolysis processes are accelerated in a facility room with high temperature and over $60 \%$ humidity. When environmental temperature rose to 2 to $3^{\circ} \mathrm{C}$ above the rats' tolerance limits, in the first 50 min, clinical signs were observed: tachycardia, tachypnea, animal removes bedding. It was observed that rats' body temperature: 44.3 to $45.7^{\circ} \mathrm{C}\left(42.5^{\circ} \mathrm{C}\right.$ environmental temperature $)$ causes ani$\mathrm{mal}$ death in 63 to $132 \mathrm{~min}$. Animal survival is reduced at 
temperatures below $0^{\circ} \mathrm{C}$. In the first minutes after exposure to environmental temperatures of $0^{\circ} \mathrm{C}$, animals tried to accommodate by reducing heart rate and respiratory rate, reducing floor space (Gordon, 1993).

Relative humidity variations are less important than temperature variations. A relative humidity below $40 \%$ increases the proportion of respiratory infections and skin lesions. High air humidity generates heat stress, increase ammonia concentrations (over 500 ppm) and decrease infection resistance.

Opposed to occupational hygiene, the veterinary hygiene does not impose regulatory limits regarding the lighting uniformity. The recommendation of the occupational hygiene for a static work is a uniformity factor of $1 / 4$ to $1 / 8$, and for a moving work, when necessary light has to be provided from multiple directions, a uniformity factor around $1 / 2$ to $1 / 3$ is recommended (Directive 86/609 (EEC). Castelhano-Carlos et al. (2009), showed that a light intensity higher than $572 \mathrm{~lx}$ inhibits social interaction of young Wistar rats. In bright light, normal behaviors, such as crunching, playing are inhibited. It is known that playful activity is a behavior that expresses the welfare of farm and laboratory animals. The same study shows that albino rats avoid white light intensity greater than $25 \mathrm{~lx}$, preferring more a red light.

Considering carbon dioxide, we found that there is no indication in the European or the American Codes of Good Practice for rodents, with regards to the admitted maximum limit in laboratory animal facilities, but some authors suggest that the acceptable maximum limits for rodents should be identical with the maximal exposure limits for humans, which is eight hours work period, $(5,000$ ppm) (Ciudin, 2004). Other authors (Krohn and Hansen, 2000), considered that, for laboratory animals, this value should be reduced to half. In a laboratory animal facility, airborne particles represent a major source of allergens both for workers and animals. Animal health is a welfare indicator used both for farm and laboratory animals (Kaliste, 2002; 2004).

Considering ISO 14644-1:1999 classification of environment contamination according to airborne particles diameter, both animal laboratory facility belongs to level 7 (on a scale ranging from 1 to 9 ). This is equivalent to an environment well contaminated with particles, with allergenic potential to human and animals (ISO, 1999).

The recoded values for airborne microorganism are comparable with those obtained by Kaliste et al. (2004), during bedding change. However, these values, in B laboratory animal facility, are well below those reported from other animal facilities, such as poultry confinement buildings $\left(36.000 \pm 7.400\right.$ C.F.U. $\left./ \mathrm{m}^{3}\right)$ or swine buildings (20.000 \pm 60.000 C.F.U. $/ \mathrm{m}^{3}$ (Carpenter et al., 1986a; Carpenter et al.,1986b). The concentration of viable fungi, 943 C.F.U./cubic meter before changing bedding in B facility, was like those reported in others studies (Kaliste et al., 2004). But in A facility, the mean value for TMB is lower.
Differences between the two studied laboratory animal facilities, regarding microbiological factors were recorded. The physical and chemical factors had similar values, the values recorded for particles and microorganisms showed significant differences, because of different facility equipment. Using bedding changing station in facility $A$ and cages with their own ventilation, and also a ventilation system for each room, the dust particles number and airborne microorganisms decreased considerably. Values obtained for airborne microorganisms for facility A, proved good air quality, while in facility $B$, the lack of a proper ventilation system and the bedding change way led to an increased air germ load.

This study is important to Romanian researchers because it offers an image of facilities' conditions, laboratory animals' health and analyzes the used animal facilities deficiencies. We proposed, the use, in animal facilities, a separate room for each species, increasing bedding frequency (two times/week), cage with individual ventilation and surveillance animal laboratory health.

\section{REFERENCES}

Brielmeier M, Mahabir E, Needham J R, Lengger C, Wilhem P, Schmidt J. (2006). Microbiological monitoring of laboratory mice and biocontainment in individually ventilated cage: a field study. Laboratory Animals 40:247-260.

Castelhano-Carlos M J, Baumas V (2009). The impact of light, noise, cage cleaning and in house transport on welfare and stress of laboratory rats Laboratory animals 43:311-327.

Ciudin E (2004). Laboratory animals' biology (in Romanian). Alfa Press, lasi, Romania pp. 3-72.

Council Directive 86/609/EEC of 24 November (1986) on the approximation of laws, regulations and administrative provisions of the Member States regarding the protection of animals used for experimental and other scientific purposes. Official Journal of the European Union. L 358/1-29. http://eurlex.europa.eu/LexUriServ/LexUriServ.do?uri=OJ:L:1986:358:0001:00 28:EN:PDF

Directive 2010/63/EU of the European Parliament and the Council of 22 September 2010 on the protection of animals used for scientific purposes. Official Journal of the European Union. L 276/33-79. http://eur-

lex.europa.eu/LexUriServ/LexUriServ.do?uri=OJ:L:2010:276:0033:00 79:en:PDF

Decun M, Nichita I, Tibru I, Lazarescu C (2005). Handbook for animals and environmental hygiene (in Romanian). Mirton Press, Timisoara, Romania pp.9-78.

Carpentera GA, Smithb WK, MacLarenb APC, Spackmanc D (1986a). Effect of internal air filtration on the performance of broilers and the aerial concentrations of dust and bacteria. Brit. Poultry Sci. 27:471480.

Carpenter GA, Cooper A, Wheeler GE (1986b). The effect of air filtration on air hygiene and pig performance in early-weaner accommodation. Anim. Prod. 43:505-515.

Gordon JC (1993. Temperature regulation in laboratory rodents, Ed. Cambridge University Press, UK.

Gordon S, Fisher W S, Raymond HR (2001) Elimination of mouse allergens in the working environment. Assessment of individually ventilated cages systems and ventilated cabinets in the containment of mouse allergens. J. Allergy Clin. Imunol. 108(2):288-294.

Institute of Laboratory Animal Resources (ILAR) (1996). National Research Council. Guide for care and use of laboratory animals. National Academy Press, Washington DC, 1996; 21-55, www.nap.edu/openbook.php?record_id=5140) 
ISO 14644-1:1999 Cleanrooms and associated controled environments. Classification of air cleanliness by particle concentration.

Kaliste E, Linnainmaa M, Meklin T, Nevalainen A (2002). Airborne contaminants in conventional laboratory rabbit room. Lab. Anim. 36:43-50.

Kaliste E, Linnainmaa M, Meklin T, Torvinen E, Nevalainen A (2004). The bedding of laboratory animals as a source of airborne contaminants. Lab. Anim. Sci. 38:25-37.
Krohn T, Hansen AK (2000). The effects and tolerances for carbon dioxide in relation to recent developments in laboratory animal housing. Scandinavian J. Lab. Anim. Sci. 27, 3:173-182.

Kowalski WJ, Bahnfleth WP, Carey DD (2002). Engineering Control of Airborne Disease Transmission in Animal Laboratory. Contemporary Topics, 41(3):9-18. 